University of Wollongong

Research Online

Faculty of Engineering and Information

Faculty of Engineering and Information

Sciences - Papers: Part A

Sciences

$1-1-2013$

\title{
Microstructural characterization of P91 steel in the virgin, service exposed and post-service re-normalized conditions
}

Huijun Li

University of Wollongong, huijun@uow.edu.au

David Mitchell

Sasol Technology Research and Development, Johannesburg, dmitchel@uow.edu.au

Follow this and additional works at: https://ro.uow.edu.au/eispapers

Part of the Engineering Commons, and the Science and Technology Studies Commons

Research Online is the open access institutional repository for the University of Wollongong. For further information contact the UOW Library: research-pubs@uow.edu.au 


\title{
Microstructural characterization of P91 steel in the virgin, service exposed and post-service re-normalized conditions
}

\author{
Abstract \\ P91 steel has been widely used in power generation industry. Generally, P91 creep resisting steel is \\ produced by normalizing and tempering. The normalizing temperature is in the range of $1040-10808 \mathrm{C}$ \\ and tempering temperature is in the range of $750-7808 \mathrm{C}$. The microstructure after tempering is tempered \\ martensite with precipitates of carbides, M23C6, and vanadium/niobium rich carbo-nitride of the type MX \\ $(\mathrm{M} 1 / 4 \mathrm{~V}$ or $\mathrm{Nb}$ and $\mathrm{X} 1 / 4 \mathrm{C}$ or $\mathrm{N}$ ). The presence of carbide precipitates improves creep rupture strength due \\ to precipitation hardening. The carbide coarsening and microstructure degradation during service will \\ result in deterioration in creep strength. It is important to understand the microstructural evolution of P91 \\ steel during long-term operation. In this work, the steels in the virgin condition (normalized and \\ tempered), service exposed (9 years at 6008C) and post service exposed re-normalized and tempered in \\ an attempt to restore the original microstructure were characterized. A range of microscopy techniques, \\ predominantly TEM, were applied to understand the effect of these thermal histories on the \\ microstructure of the materials.
}

\section{Keywords}

microstructural, conditions, normalized, re, post, exposed, service, virgin, steel, p91, characterization

\section{Disciplines}

Engineering | Science and Technology Studies

\section{Publication Details}

Li, H. \& Mitchell, D. (2013). Microstructural characterization of P91 steel in the virgin, service exposed and post-service re-normalized conditions. Steel Research International, 84 (12), 1302-1308. 


\title{
Microstructural Characterization of P91 Steel in the Virgin, Service Exposed and Post-Service Re-Normalized Conditions
}

\author{
Huijun Li* and David Mitchell
}

\begin{abstract}
P91 steel has been widely used in power generation industry. Generally, P91 creep resisting steel is produced by normalizing and tempering. The normalizing temperature is in the range of $1040-1080^{\circ} \mathrm{C}$ and tempering temperature is in the range of $750-780^{\circ} \mathrm{C}$. The microstructure after tempering is tempered martensite with precipitates of carbides, $\mathrm{M}_{23} \mathrm{C}_{6}$, and vanadium/niobium rich carbo-nitride of the type $M X(M=V$ or $N b$ and $X=C$ or $N)$. The presence of carbide precipitates improves creep rupture strength due to precipitation hardening. The carbide coarsening and microstructure degradation during service will result in deterioration in creep strength. It is important to understand the microstructural evolution of P91 steel during long-term operation. In this work, the steels in the virgin condition (normalized and tempered), service exposed ( 9 years at $600^{\circ} \mathrm{C}$ ) and post service exposed re-normalized and tempered in an attempt to restore the original microstructure were characterized. A range of microscopy techniques, predominantly TEM, were applied to understand the effect of these thermal histories on the microstructure of the materials.
\end{abstract}

\section{Introduction}

P91 steel, which belongs to 9-12\% Cr ferritic creep resisting steel group, was developed for elevated temperature service for nuclear and fossil energy applications, it is a modified $9 \%$ Cr-1\%Mo creep resisting steel that provides significantly higher design stress values than A335 P9. The modification consists of addition of vanadium, niobium, and nitrogen and narrowing of the maximum compositional ranges of carbon, chromium, silicon, molybdenum, phosphorus, and sulfur. P91 creep resisting steel is being increasingly used for elevated temperature service in the power generating and process industries for components such as headers, superheaters, and reheaters, because of its attractive thermal properties and enhanced creep and oxidation resistance, P91 steel is commonly used in the temperature range from 540 to $650^{\circ} \mathrm{C}$. In this temperature range the engineering design requirements will be dominated by the creep performance behavior of the material compared to short-term properties such as elevated-temperature tensile strength. ${ }^{[1-5]}$

Mechanical properties of P91 creep resisting steel, and similar grades conforming to ASTM A335, are a yield strength of $415 \mathrm{MPa}$ (minimum), tensile strength of $585 \mathrm{MPa}$ (minimum), longitudinal elongation of $20 \%$ (minimum), and a maximum hardness of HB 250 at room temperature. The minimum creep rupture strength at $625^{\circ} \mathrm{C}$ is $68 \mathrm{MPa}$.

\section{Experimental}

Table 1 shows the chemical composition of the $50 \mathrm{~mm}$ thick P91 pipe steel that was investigated in the current work. The P91 pipe steel was in the normalized and tempered (NT) condition. The as received P91 pipe has a structure consisting of tempered martensite with an average hardness of 224 HV10.

Three specimens from P91 boiler tubing were provided for microstructural characterization. The steels were in the virgin condition (normalized and tempered), service exposed (9 years at $600^{\circ} \mathrm{C}$ ) and post-service exposed renormalized and tempered in an attempt to restore the original microstructure. A range of microscopy techniques, predominantly TEM, were applied to understand the effect of these thermal histories on the microstructure of the materials. 


$\begin{array}{lccccc}\text { Element } & \mathrm{C} & \mathrm{Mn} & \mathrm{Si} & \mathrm{Cr} & \mathrm{Ni} \\ & 0.09 & 0.40 & 0.28 & 8.50 & 0.15 \\ \text { Element } & \mathrm{Nb} & \mathrm{Cu} & \mathrm{V} & \mathrm{N} & \mathrm{Mo} \\ & 0.06 & 0.16 & 0.21 & 0.052 & 0.89\end{array}$

Table 1. The chemical composition (wt\%) of the P91 steel used in the investigation.

Standard metallographic samples were prepared for optical microscopy, hardness, and scanning electron microscopy. These were also used to prepare extraction replicas (single stage method) taken perpendicular to the axis of the pipe. Thin foils of the steels were prepared by cutting thin wafers of metal from the pipe section with a slow speed saw, such that the wafer's normal was parallel to the axis of the pipe. Three millimeters discs were punched from the wafers and were ground to $\approx 80 \mu \mathrm{m}$ thickness. They were then double-sided electropolished in a Struers Tenupol 3, using a solution of $4 \%$ perchloric acid in methanol at $-40^{\circ} \mathrm{C}$, using a total current of $160 \mathrm{~mA}$. Discs were stored in dry air prior to examination. TEM examination was carried out in a JEOL 200FXII TEM with a wide bore polepiece designed for working with ferromagnetic materials. Quantitative analysis of carbides was achieved using the calibrated energy dispersive spectroscopy (EDS) system on this instrument.

\section{Results and Discussion}

\subsection{Hardness}

The hardness results (Table 2) showed the marked softening of P91 which occurred due to service. This steel softened from an initial hardness of $225 \mathrm{Hv}$ (B629) to only $145 \mathrm{Hv}$ after service exposure (B628). The re-normalization heat treatment to restore the initial properties of the steel was extremely successful with respect to the hardness, since the post-heat treatment hardness $(220 \mathrm{Hv})$ was almost identical to that of the virgin steel $(225 \mathrm{Hv})$.

\subsection{Optical Microscopy}

The virgin steel exhibited a microstructure typical of tempered martensite (Figure 1). The prior austenite grain

\begin{tabular}{llll}
\hline & Virgin & Ex-service & Re-normalized \\
\hline Hardness & 225 & 145 & 220 \\
\hline
\end{tabular}

Table 2. Hardness of P91 in the three conditions.

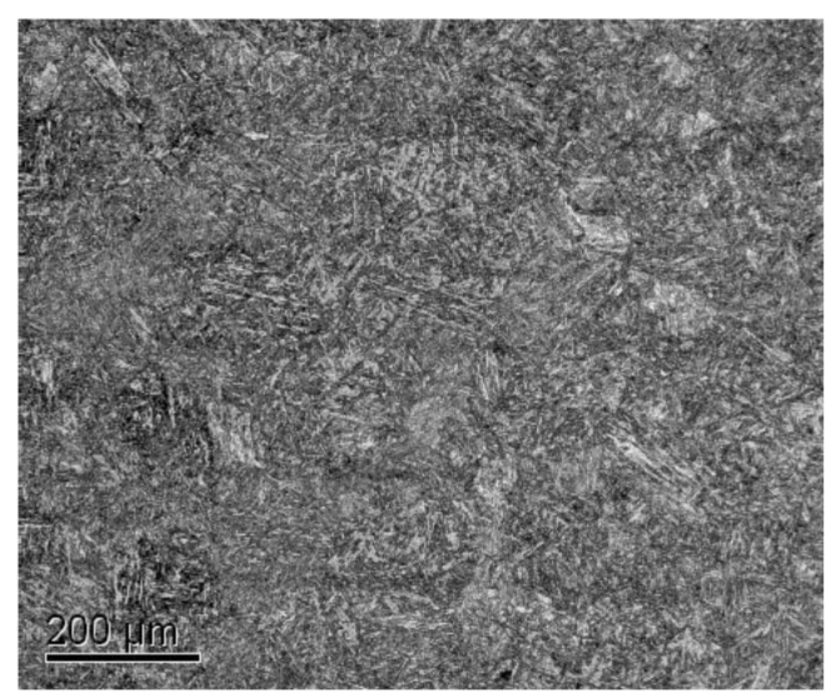

Figure 1. Virgin Steel - optical micrographs showing the tempered martensitic structure.

boundaries were not very apparent, nor were carbides. There was some indication of micron-sized particles, but the superior resolution of TEM was required to characterize these.

The microstructure of the service-exposed steel (Figure 2) was modified as a result of time at temperature, when compared with the virgin steel (Figure 1). The equiaxed grain structure in the service exposed material was in marked contrast to the tempered martensitic structure of the virgin steel. The mean grain size in the service exposed material was about $25 \mu \mathrm{m}$. Detailed observation showed the presence of carbides. These were

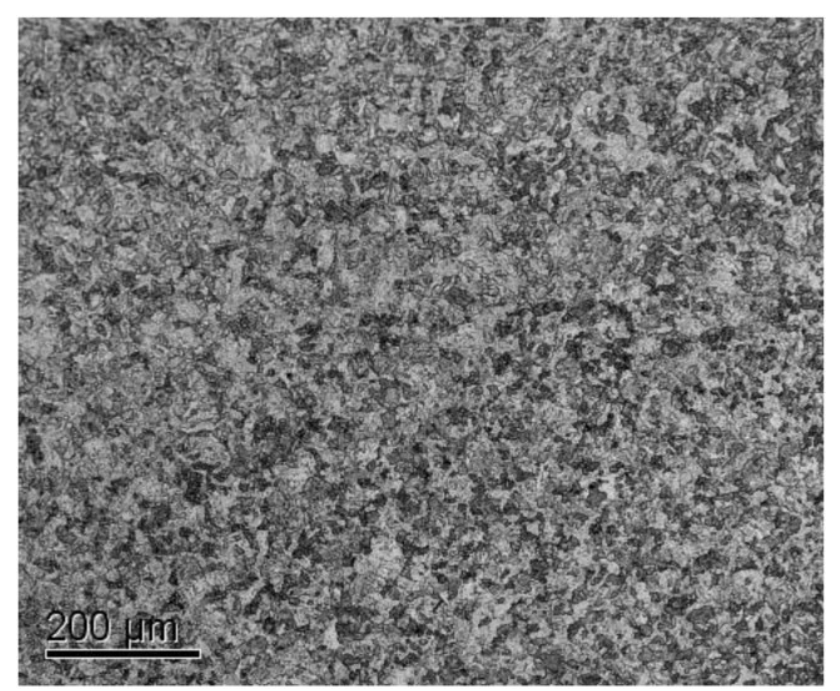

Figure 2. Service-exposed steel, the microstructure has changed to an equiaxed one in sharp contrast to the tempered martensitic structure of the virgin steel. 


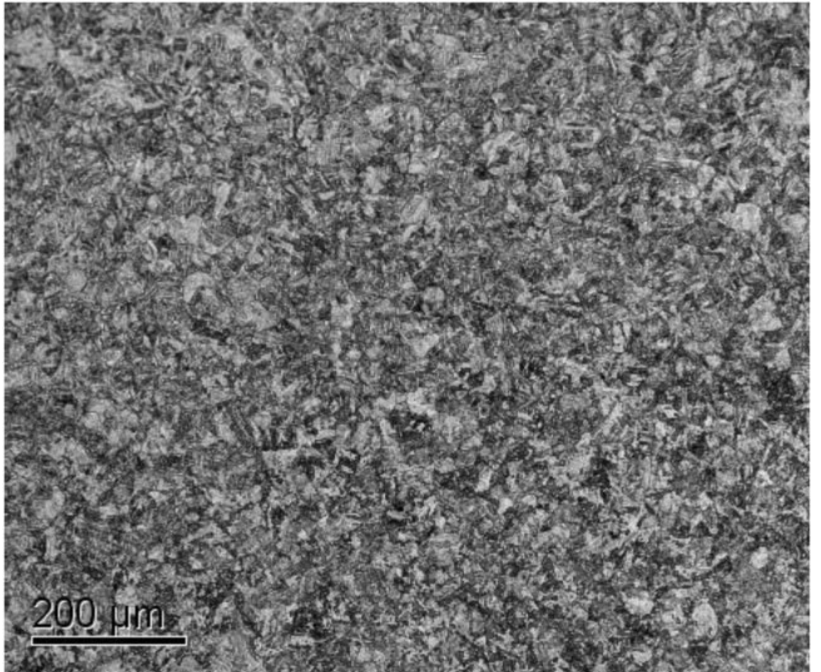

Figure 3. Re-normalized steel, the microstructure is martensitic, but the grains are very evident, far more so than in the virgin steel.

arranged in parallel rows within grains, reflecting their location along the former martensite lath boundaries.

Low powered optical microscopy showed the grain structure of re-normalized steel, with grain sizes in the range $20-40 \mu \mathrm{m}$ (Figure 3). This grain structure was more apparent in the re-normalized service exposed material compared with virgin steel. The martensitic lath structure was evident. However, comparison with that of the virgin steel showed that the lath uniformity of the renormalized steel was more irregular than that of the virgin steel, and the prior austenite grain boundaries were much more apparent. Carbides were visible in both microstructures, being of similar dimensions.

\subsection{TEM-Examination}

A region of the thin foil was tilted close to [001] (Figure 4, insert) and pronounced lath structure became apparent (Figure 4). The long axes of the laths was parallel to [100]. The lath structure was fairly uniform, with a mean lath width of about $0.4 \mu \mathrm{m}$. Under appropriate two beam conditions dislocation structures were evident within the laths as sub-grains, while the density of discrete dislocations within the laths was not high. More detailed examination of the laths (Figure 5) showed the presence of some coarse carbides. These were generally on the lath boundaries, and were elongated parallel to the long axes of the laths. Carbides were 50-150 nm wide and up to $300 \mathrm{~nm}$ long. Qualitative EDS analysis of the carbides showed that they were Cr-rich. A very small number of what appeared to be fine carbides, as well as individual dislocations, were present within laths. These fine scale carbides could not be analyzed in these thin foil specimens. Quantitative analysis of the coarse carbides was possible by careful probing of

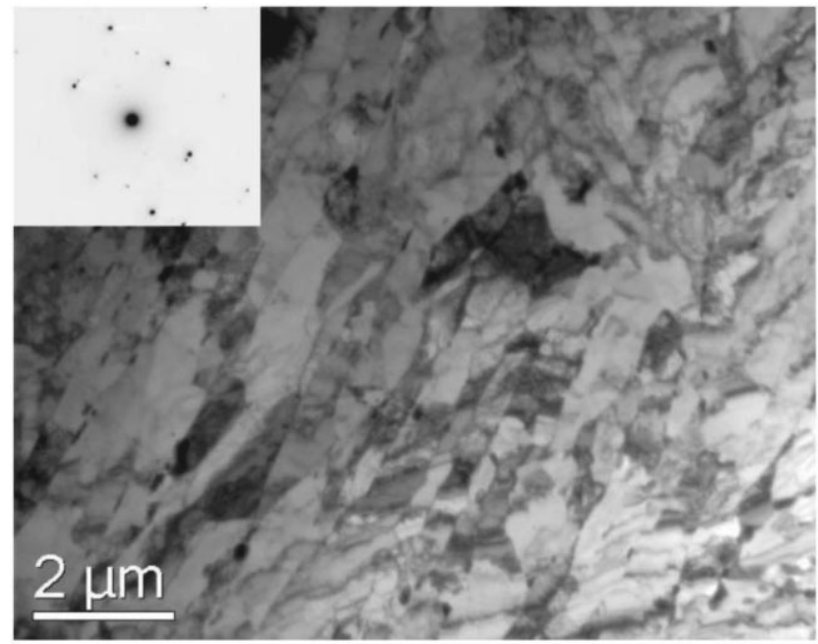

Figure 4. Virgin steel. Thin foil tilted close to [001] (insert) showing the marked lath structure running parallel to [100].

carbides, which projected out of the edge of the perforation in the foil (from jet electropolishing). These were generally attached to the foil by only a thin membrane of steel, which could be avoided during analysis.

Results of EDS of a number of coarse carbides are shown in Table 3. The composition was generally very consistent. The high Fe content in carbide 5 is probably due to proximity of the matrix - this result was omitted from the averaging. The mean composition (wt\%) was therefore $\mathrm{Cr}=54.6 \pm 1.4, \mathrm{Fe}=36.9 \pm 2.3, \mathrm{Mo}=8.2 \pm 1.3$. These carbides are most likely $\mathrm{M}_{23} \mathrm{C}_{6}$ type, where $\mathrm{M}$ is a mixture of $\mathrm{Fe}$ and $\mathrm{Cr}$, although we have not carried out diffraction analysis to confirm this.

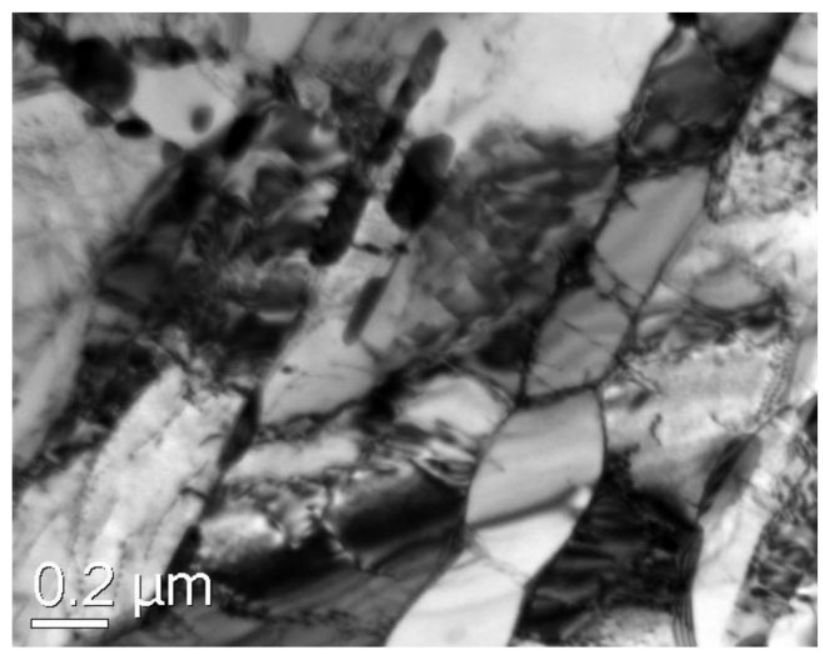

Figure 5. Virgin steel. Thin foil showing a detail of the lath structure showing Cr-rich elongated carbides mainly on the lath boundaries. 


\begin{tabular}{llll}
\hline Carbide & Cr/wt\% & Fe/wt\% & Mo/wt\% \\
\hline 1 & 55.4 & 34.8 & 9.8 \\
2 & 54.9 & 35.8 & 9.2 \\
3 & 54.6 & 37.9 & 7.4 \\
4 & 55.9 & 35.7 & 8.3 \\
5 & 49.1 & 43.2 & 7.7 \\
6 & 52.3 & 40.5 & 6.5 \\
Ferrite matrix & 9.1 & 89.4 & 1.5
\end{tabular}

Table 3. EDS analysis of coarse carbides in virgin steel.

Replication of the virgin steel (Figure 6) extracted a large proportion of the very fine carbides also seen in the thin foil specimens. These were typically sub-50 nm diameter and mainly globular. These fine carbides were arranged in lines suggesting that they tended to precipitate on the lath and subgrain boundaries. The location of the fine carbides near the lath boundaries would tend to obscure them somewhat in the thin foils because of dislocation structures, contrast changes between laths and subgrains and the presence of larger Cr-rich carbides. Also apparent in the replicas were a number of large depressions in the carbon film. These were $200-400 \mathrm{~nm}$ in diameter, being failed extractions of the coarse Cr-rich carbides, which were very apparent in the thin foil images (e.g., Figure 5). These failed extractions were also arranged in rows parallel to the rows of fine scale carbides, though slightly displaced. It is not clear why this displacement exists. This may be a

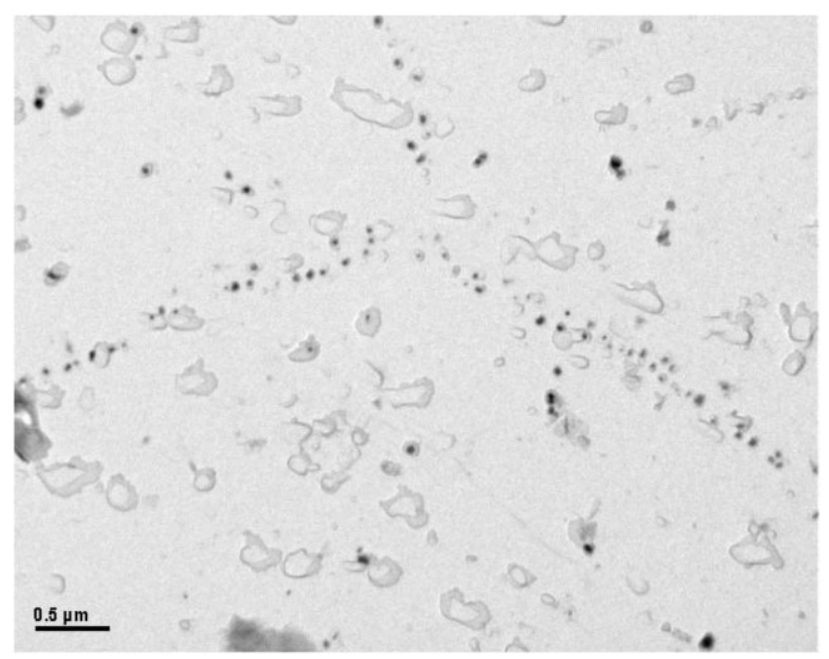

Figure 6. Virgin steel extraction replicas showing a) alignment of fine scale $\mathrm{Nb} / \mathrm{V}$-rich carbides parallel to, and slightly displaced from similar alignments of failed extractions of larger $\mathrm{Cr}$ rich carbides.

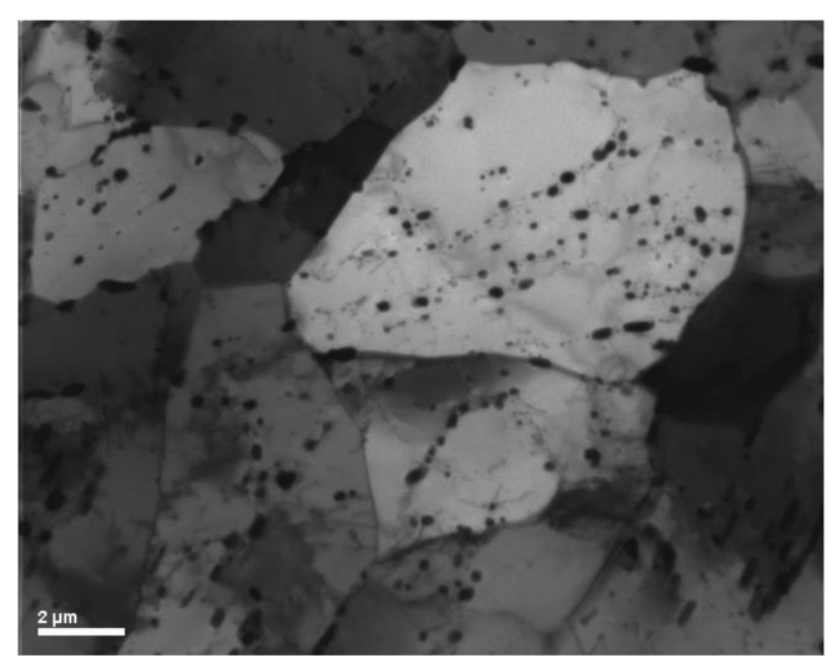

Figure 7. Service-exposed steel. Thin foil specimen showing the grains, the loss of lath and dislocation structures, and the coarse Cr-rich carbides delineating the former lath boundaries.

consequence of lath/subgrain boundary movement during tempering, combined with precipitation of the two carbide types at different stages of the tempering process.

EDS analysis of the fine scale carbides showed that they were niobium rich containing approximately $50 \mathrm{wt} \% \mathrm{Nb}$, with the balance predominantly $\mathrm{V}$.

Thin foil examination on service-exposed steel (Figure 7) highlighted the dramatic difference between this steel and the virgin material. Much of the lath and subgrain structure had been lost, with the prior austenite grain structure being evident. Average grain diameters measured optically were $\approx 25 \mu \mathrm{m}$. Within the grains the coarse carbides delineated the original lath boundaries, being arranged in parallel stripes with a spacing of about $0.4 \mu \mathrm{m}$. Clearly extensive recovery had taken place due to service exposure and the lath, sub-grain and dislocations present in the virgin steel has been lost. This recovery was also reflected in the extensive softening which occurred due to service (Table 2). Higher magnification imaging (Figure 8) highlighted the remnant lath microstructure delineated by the coarse 200-400 nm carbides. This carbide configuration was also observed in optical microscopy. Occasional fine carbides (sub-50 nm) were present both within grains and within rows of coarse carbides. The dislocation density was very much lower than in the virgin steel.

EDS analysis of the coarse carbides which protruded over the edge of the foil for service-exposed steel yielded the results shown in Table 4 . The mean coarse carbide composition (wt\%) was $\mathrm{Cr}=61.3 \pm 3.0, \mathrm{Fe}=27.2 \pm 3.3$, Mo $=9.6 \pm 1.0$. Comparison with the virgin steel showed that service exposure resulted in a small ( $\approx 7 \mathrm{wt} \%$ ), but statistically significant enrichment in $\mathrm{Cr}$ at the expense of Fe in the coarse carbides.

Extraction replication of this steel (Figure 9) again extracted the fine scale carbides, with impressions left in 


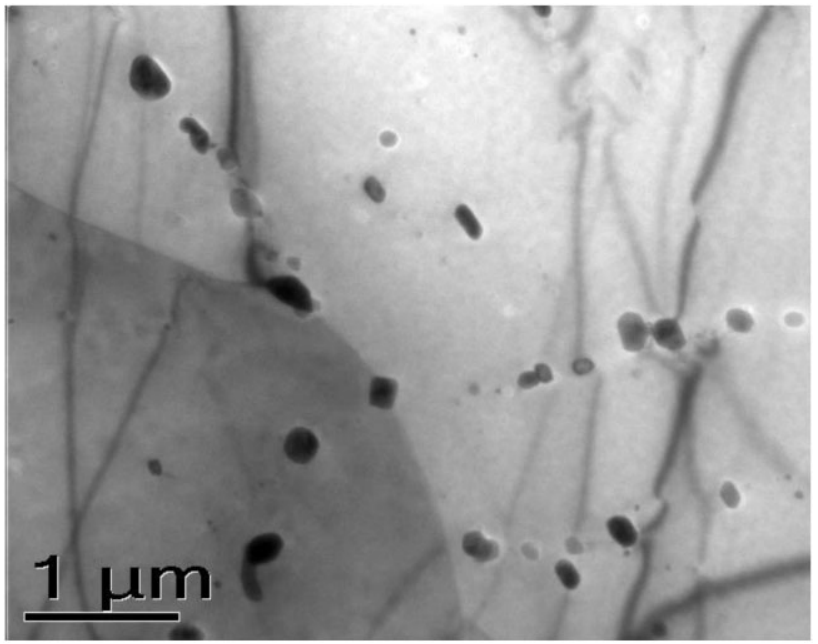

Figure 8. Service-exposed steel. Thin foil specimen. Showing a grain boundary, and coarse Cr-rich carbides within grains delineating former lath boundaries. Carbides have become less elongated and more faceted as a result of service exposure.

the carbon film of failed extractions of the larger coarse carbides. All the extracted carbides were roughly spherical, suggesting that the service exposure has caused spheroidization of these carbides. Almost all the carbides in Figure 9 are NbC. It would therefore appear that significant coarsening and some secondary precipitation of very fine $\mathrm{NbC}$ carbides has occurred due to service exposure. This also seemed to have occurred for the coarse carbides. In the virgin steel many of the carbides were elongated while after service exposure carbides tended to be more globular and in some cases strongly faceted (Figure 8). EDS analysis of the fine scale carbides showed that they were $\mathrm{Nb}$-rich containing ca $80 \mathrm{wt} \%$ of the element, with much of the

\begin{tabular}{lllc}
\hline Carbide & Cr/wt\% & Fe/wt\% & Mo/wt\% \\
\hline 1 & 62.5 & 25.7 & 8.9 \\
2 & 58.3 & 30.2 & 9.8 \\
3 & 60.7 & 28.4 & 10.2 \\
4 & 60.1 & 31.3 & 7.3 \\
5 & 58.2 & 28.9 & 9.6 \\
6 & 59.4 & 28.3 & 10.2 \\
7 & 65.3 & 22.8 & 10.6 \\
8 & 66.6 & 21.3 & 10.4 \\
9 & 60.9 & 27.7 & 9.3 \\
Ferrite matrix & 8.9 & 88.9 & 1.2
\end{tabular}

Table 4. EDS analysis of coarse carbides in service exposed steel.

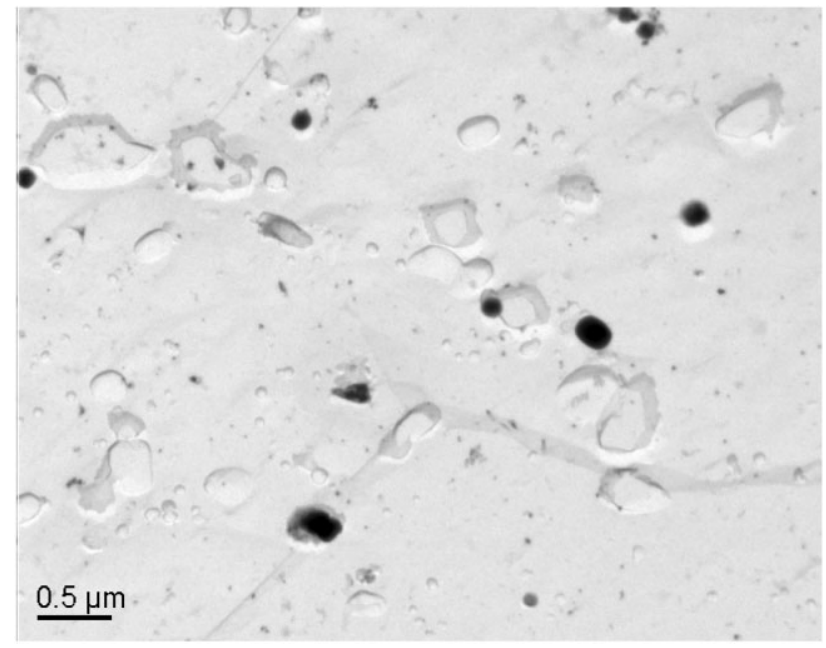

Figure 9. Service-exposed steel. Extraction replica showing the spherical fine scale $\mathrm{Nb}$-rich carbides and the impressions of larger Cr-rich carbides which failed to extract.

balance being $\mathrm{V}$. This suggested that $\mathrm{Nb}$ enrichment occurred in the fine scale carbides as a consequence of service exposure.

Low magnification imaging of a re-normalized steel thin foil (Figure 10) under imaging conditions identical to those used for the previous specimens showed that renormalizing had restored the lath microstructure seen in the virgin steel. The average lath width was also similar at about $0.4 \mu \mathrm{m}$. More detailed examination showed the presence of subgrain structures within the laths as well as elongated Cr-rich carbides on the lath boundaries. It was difficult to see fine scale precipitates against the background of dislocation contrast. This microstructure was very similar

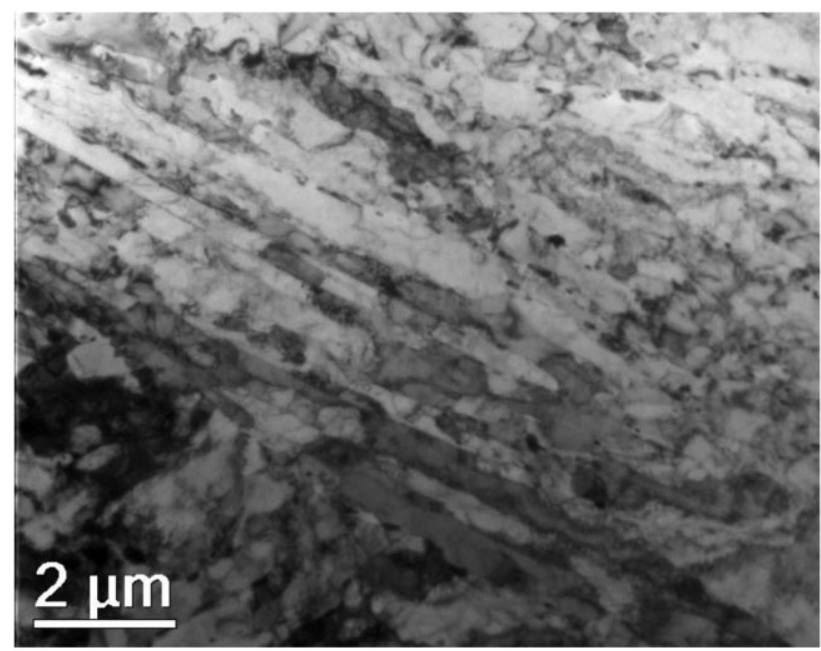

Figure 10. Renormalized steel thin foil specimen showing how the heat treatment has restored the lath and dislocation microstructure seen in the virgin steel. The mean lath width is $0.4 \mathrm{~mm}$. 


\begin{tabular}{llll}
\hline Carbide & Cr/wt\% & Fe/wt\% & Mo/wt\% \\
\hline 1 & 56.4 & 33.4 & 10.2 \\
2 & 56.2 & 32.9 & 10.9 \\
3 & 52.5 & 38.6 & 9.0 \\
4 & 55.1 & 35.1 & 9.8 \\
5 & 49.5 & 42.2 & 8.2 \\
6 & 56.8 & 32.7 & 10.5 \\
7 & 55.5 & 34.4 & 10.1 \\
8 & 55.9 & 34.1 & 10.0
\end{tabular}

Table 5. EDS analysis of coarse carbides in B627 (renormalized steel).

to the virgin steel, and this was also reflected in the very similar hardness (Table 2).

EDS analysis (Table 5) of coarse carbides at the edge of the foil for re-normalized steel showed a very consistent composition with the exception of two carbides (3 and 5) which were Fe-rich. These were omitted from the averaging which yielded a mean composition (wt\%) of $\mathrm{Cr}=56.0 \pm 0.6, \mathrm{Fe}=33.8 \pm 0.9, \mathrm{Mo}=10.2 \pm 0.4$. Within the accuracy of the measurements, this carbide composition was also identical to that of the virgin steel (Table 3).

Examination of replicas from renormalized steel sample showed that a larger proportion of the carbides has been extracted so that coarse Cr-rich as well as fine Nb-rich carbides were present on the replica (Figure 11). EDS

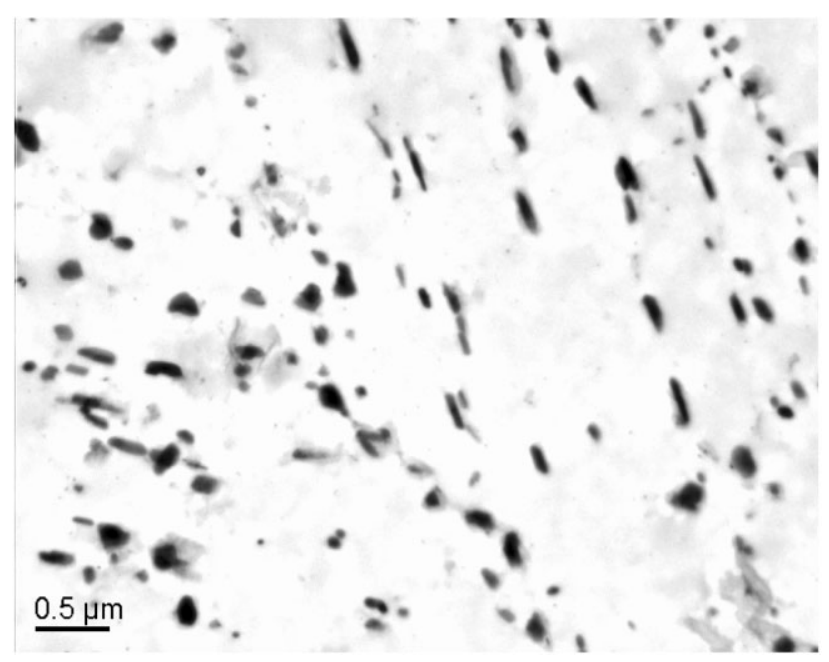

Figure 11. Renormalized steel extraction replica specimen showing how both coarse and fine carbides have been extracted. EDS analysis of the coarse carbides confirms the analysis of similar carbides projecting over the edge of thin foil specimens. analysis of the coarse scale Cr-rich carbides produced a mean composition very similar to that reported above. As well as the coarse elongated carbides $(\approx 200 \mathrm{~nm}$ long$)$, which outlined the lath microstructure, there were some fine Cr-containing carbides present. These were very fine $\approx 20 \mathrm{~nm}$. However, none of these were $\mathrm{NbC}$.

\section{Conclusions}

The microstructure of virgin P91 steel comprises a complex microstructure of tempered martensite laths with a mean diameter of $\approx 0.4 \mu \mathrm{m}$. These contain some dislocation structure. Two carbide phases were present in these materials. Optical microscopy and thin foil TEM specimens highlighted a coarse Cr-rich carbide $\left(\mathrm{M}_{23} \mathrm{C}_{6}\right) 200$ $400 \mathrm{~nm}$ in length, elongated parallel to the lath axes. Extraction replication also revealed the presence of a population of fine $(\approx 50 \mathrm{~nm}) \mathrm{Nb}$-rich carbides, which also contained $\mathrm{V}$.

Service exposure resulted in very extensive recovery of the lath and dislocation microstructure. This produced an equiaxed grain microstructure with grain diameters of up to $25 \mu \mathrm{m}$. Within the grains the coarse carbides delineated the original lath boundaries. Extensive recovery of the dislocation structure also occurred, with very low dislocation densities within the grains of the service exposed material. Carbides were modified by service exposure. Some spheroidization of the coarse Cr-rich carbides occurred as did compositional change with a small $(\approx 7 \mathrm{wt} \%)$ but significant enrichment in $\mathrm{Cr}$ occurring at the expense of Fe. Extraction replication showed that the fine scale carbides also coarsened and spheroidized due to service exposure, and considerable enrichment in $\mathrm{Nb}$ occurred at the expense of $\mathrm{V}$. The microstructural differences between the virgin and the service exposed steel were reflected in the very significant softening which occurred, the virgin steel hardness of $225 \mathrm{Hv}$ being reduced to $144 \mathrm{Hv}$ due to service exposure.

Attempts to restore the original microstructure of the service exposed steel by renormalizing and tempering it appear to have been very successful. Optical microscopy suggested that the grain structure was more apparent in the renormalized steel than the virgin steel. However, TEM examination showed that the microstructural differences between the two steels were quite small. The lath microstructure was restored by renormalization, producing laths with similar widths $(0.4 \mu \mathrm{m})$, dislocation structures and with lath boundaries decorated by coarse Cr-rich carbides of identical composition and size to those in the virgin material. This similarity in microstructure was reflected in the hardness of the renormalized material $(220 \mathrm{Hv})$ which was almost fully restored to that of the virgin steel $(225 \mathrm{Hv})$. 


\section{References}

[1] W. Bendick, K. Niederhoff, G. Wellnitz, M. Zschau, H. Cerjak, (1992), 'The Influence of Welding on Creep Rupture Strength of $9 \%$ Cr Steel P91', Proc. $3^{\text {rd }}$ Int. Conf.
On Trends in Welding Science and Technology, ASM International, pp. 587-598.

[2] H. K. D. H. Bhadesia, Keynote address: Design of creep resistant welding alloys, Proc.5th. Int. Conf. on Trends in Welding Research, ASM International 1998, pp. 795804.

[3] P. J. Ennis, A. Czyrska-Filemonowicz, OMMI 2002, 1 (1), 1-28.

[4] L. Resenbrack, Aust. Welding J. 2001, 46, 5-8.

[5] K. Maruyama, K. Sawada, J. Koike, ISIJ Int. 2001, 41(6), 641-653. 